\title{
Trends and driving forces of China's virtual land consumption and
}

\author{
trade \\ Xu Tian ${ }^{\mathrm{a}, \mathrm{c}, *}$, Martin Bruckner ${ }^{\mathrm{b}}$, Yong Geng ${ }^{\mathrm{a}, \mathrm{d}, \mathrm{e}, *,}$, Raimund Bleischwitz $^{\mathrm{c}}$ \\ a School of International and Public Affairs, Shanghai Jiao Tong University, Shanghai, 200240, \\ China \\ b Institute for Ecological Economics, Vienna University of Economics and Business, 1020, Vienna, \\ Austria \\ c Institute for Sustainable Resources, University College London, Central House, 14 Upper Woburn \\ Place, London, WC1H 0NN, United Kingdom \\ d China Institute of Urban Governance, Shanghai Jiao Tong University, Shanghai, 200240, China \\ e Shanghai Institute of Pollution Control and Ecological Security, Shanghai, 200092, China \\ Corresponding authors: tianxu@sjtu.edu.cn (X. Tian),ygeng@sjtu.edu.cn (Y. Geng)
}

\begin{abstract}
Land resources are important for China's rapid economic development, especially for food and construction. China's land resources are under tremendous pressures, and therefore land use is increasingly displaced to other parts of the world. This study analyses the evolution and driving forces of China's land consumption from 1995 to 2015. The main results show that China's land footprint increased from $8.8 \%$ of the global land resources under human use in 1995 to $15.7 \%$ in 2015 . China's domestic land resources are mainly used for serving domestic consumption. Moreover, China needs to import virtual land from foreign countries to satisfy $30.8 \%$ of its land demand. Among the three land use types of cropland, grassland and forests, grassland had the largest fraction in China's land footprint from 1995 to 2000, while forest has become the largest one from then on. Trends in China's virtual land trade reveal a sharp increase in net imports from $9.4 \mathrm{E}+04 \mathrm{~km}^{2}$ in 1995 to $3.4 \mathrm{E}+06 \mathrm{~km}^{2}$ in 2015 . Observing China's virtual land network by a cluster analysis, this study concludes that China keeps tight relationships with Australia, Japan, Brazil and Korea for its cropland consumption, and Canada, USA, Mexico, Australia, Korea and Japan are relevant for its grassland consumption. In addition, a decomposition analysis shows that affluence is the major driving factor for China's land consumption, while changes in land use intensity could mitigate some of the related effects. Lastly, governance implications and policy recommendations are proposed so that China can move toward sustainable land management.
\end{abstract}

Keywords: land footprint; input-output analysis; driving forces; virtual land trade; China 


\section{Introduction}

Land is critical for driving economic activities worldwide (Giljum et al., 2009; FischerKowalski et al., 2015). Increasing population, improving the quality of life worldwide as well as the economic globalization have resulted in expanding land demand (Weinzettel et al., 2013). Under such circumstances, land use is putting increasing pressure on the environment, mainly through deforestation, ecosystem degradation, and biodiversity loss as well as by adversely affecting the global carbon and nutrient cycles (Salvo et al., 2015; Tukker and Dietzenbacher, 2013; Turner et al., 2007). To address the international drivers and responsibilities, footprint-type of indicators are increasingly applied for resource management (Bruckner et al., 2015; Hoekstra and Wiedmann, 2014).

A footprint is an indicator of human pressure on the environment that tracks the total amount of environmental emissions or resources consumption to directly and indirectly support human activities. It thus reflects the complex interactions between ecosystems and socioeconomic systems along international supply chains and addresses the responsibility of final consumers (Giljum et al., 2016; Hoekstra and Wiedmann, 2014). The footprint concept was initially put forward in the early 1990s with the "ecological footprint" indicator (Rees and Wackernagel, 1992). In order to differentiate across resource categories and develop a reliable method, new footprint indicators have been developed on water (Hoekstra and Mekonnen, 2012), carbon dioxide (Hertwich and Peters, 2009), energy (Wiedmann, 2009), materials (Bruckner et al., 2012), land (Ruiter et al., 2017), and nitrogen (Cui et al., 2016); other footprints address biodiversity (Lenzen et al., 2012), particulate matter 2.5 (Yang et al., 2017), human toxicity and eco-toxicity (Nordborg et al., 2017) for monitoring sustainability at varying levels.

The land footprint (LF) is at the core of this contribution. It is defined as the amount of land resources directly and indirectly used to produce goods and services accounted from a consumption perspective (Weinzettel et al., 2013). It thereby not only explores the resource use within a place, but also reveals the dependency of consumption in one place on resource supply from other places (Bosire et al., 2016; Bruckner et al., 2015). Many studies have explored the LF from different perspectives and at varying scales: global (Vivanco et al., 2017; Weinzettel et al., 2013), national (Han and Chen, 2018; O'Brien et al., 2015; Ruiter et al., 2017; Salvo et al., 2015; Steenolsen et al., 2012; Tukker et al., 2016), regional (Lee, 2015), sectoral (Ivanova et al., 2016) and product-level (Bosire et al., 2016; Bosire et al., 2015; Khoo, 2015; Ridoutt et al., 2014). Furthermore, with the rapid development of economic globalization, virtual land (VL) embodied in traded commodities has gained attention (Tian et al., 2018a). All studies show that international trade may allow one country to partially decouple its domestic economic and ecological systems while consuming goods from other national economic systems and shifting environmental pressures abroad (Weinzettel et al., 2013).

The scale of China requires special attention. With the rapid economic development, urbanization and population growth, China's land use is under tremendous pressures (Qiang et al., 2013). On the one hand, land requirements to meet 
domestic demand have increased significantly (Weinzettel et al., 2013); on the other hand, land degradation has become a serious issue in China. For instance, it is reported that the annual cost of land degradation in China reached US\$ 37 billion or about $1 \%$ of China's GDP in 2007 (Nkonya et al., 2016). In order to identify trade-related sustainability issues and in search for useful solutions in the context of economic globalization, several studies focus on China's LF and VL. For example, Chen and Han (2015) revealed an internal transition and trade imbalance of China's virtual land use from 2002 to 2010 and highlighted the different types of industrial land consumption. Qiang et al. (2013) tried to explore China's virtual land use embodied in its crop trade from 1986 to 2009, showing that the increasing net imports of virtual land were due to China's trade in oil crops, and South America and North America were the major sources. This study highlighted the virtual land trade at the product level, and emphasized the land saving function of international trade. Ivanova et al. (2015) identified China's land footprint induced by household consumption in 2007 using environmentally extended multiregional input-output analysis. This study compared the level of land footprint in different countries. More recently, Han and Chen (2018) assessed the virtual arable land shifts embodied in China's foreign trade in 2012 at the sectoral level, revealing that China was the net importer of virtual arable land. Ali et al. (2017) presented updated results for virtual land embodied in China's food trade for 2000-2015, and projections for 2030, showing that soybean imports have been the main contributor to domestic land savings.

Different from these findings, our study aims to provide more detailed insights in a key concern for footprint analysis: the interrelation between consumed products and main land use types. In doing so, we will identify international trade clusters and uncover the driving forces of China's LF and VL changes. Such a scope is relevant in order to understand sustainable consumption patterns for an emerging economy with huge impacts across the planet. Our paper organized along three significant questions: (1) What are the characteristics of the evolution of China's LF and VL trade for three specific types of land? (2) What are the characteristics of the evolution of China's virtual land trade network? (3) What are the major driving forces of the changes in China's virtual land consumption? In order to address these issues, this study explores the evolution of China's LF and VL trade from 1995 to 2015 through multi-regional input-output analysis and cluster analysis. Furthermore, the driving forces of China's land consumption changes are identified based on index decomposition analysis. These methods will be described further down below. Our findings could provide valuable insights for China's efforts toward an 'ecological civilization' and to design a more sustainable land use system in international partnerships as well as for supply chain actors.

The remainder of this paper is as below. Section 2 introduces methods and data available of this study. Section 3 shows the major results. Furthermore, discussion and policy implications are proposed in Section 4. Finally, Section 5 makes the conclusion of this study and provides directions for future study. 


\section{Methods and data}

\subsection{Multi-regional input-output analysis}

The input-output analysis method was originally proposed to explore the transactions between economic sectors, households and government (Leontief, 1936). In order to uncover resource consumption and environmental emissions across the whole supply chain, the extended and integrated multi-regional input-output (MRIO) method was further proposed for footprint accounting (Evans et al., 1955; Miller and Blair, 2009; Peters et al., 2011). In this study, the global MRIO was applied for China's LFs accounting.

According to the MRIO method, the relationship between intermediate and final consumption and total output in each region can be expressed by equation (1).

$$
\mathrm{x}^{\mathrm{r}}=\mathrm{Z}^{\mathrm{rr}}+\mathrm{y}^{\mathrm{rr}}+\sum_{\mathrm{s} \neq \mathrm{r}} \mathrm{e}^{\mathrm{rs}}=\mathrm{A}^{\mathrm{rr}} \mathrm{x}^{\mathrm{r}}+\mathrm{y}^{\mathrm{rr}}+\sum_{\mathrm{s} \neq \mathrm{r}} \mathrm{A}^{\mathrm{rs}} \mathrm{x}^{\mathrm{s}}+\sum_{\mathrm{s} \neq \mathrm{r}} \mathrm{y}^{\mathrm{rs}}
$$

Where $\mathrm{x}^{\mathrm{r}}$ is the total output in region $\mathrm{r}$; matrix $Z^{r r}$ and vector $y^{r r}$ represent domestic intermediate consumption in region $r$ and domestic final consumption (includes households, governments and gross fixed capital formation), respectively; the bilateral trade $e^{r s}$ represents exports from region $r$ to $s$; matrix $A^{r r}$ represents the domestic direct requirement coefficients between different sectors in region $r$; matrix $A^{r s}$ represents exported direct requirement coefficients from region $r$ to $s . A^{r s} x^{s}$ and $y^{r s}$ represent exports for intermediate use and final consumption, respectively.

Equation (1) can be further expressed as equation (2) by considering the local conditions in different regions.

$$
\left(\begin{array}{c}
x^{1} \\
x^{2} \\
x^{3} \\
\vdots \\
x^{m}
\end{array}\right)=\left(\begin{array}{ccccc}
A^{11} & A^{12} & A^{13} & \cdots & A^{1 m} \\
A^{21} & A^{22} & A^{23} & \cdots & A^{2 m} \\
A^{31} & A^{32} & A^{33} & \cdots & A^{3 m} \\
\vdots & \vdots & \vdots & \ddots & \vdots \\
A^{m 1} & A^{m 2} & A^{m 3} & \cdots & A^{m m}
\end{array}\right)\left(\begin{array}{c}
x^{1} \\
x^{2} \\
x^{3} \\
\vdots \\
x^{m}
\end{array}\right)+\left(\begin{array}{c}
\sum_{r} y^{1 r} \\
\sum_{r} y^{2 r} \\
\sum_{r} y^{3 r} \\
\vdots \\
\sum_{r} y^{m r}
\end{array}\right)
$$

Where the interactions between industries and countries per unit of output are presented by matrix $A$. Equation (3) shows how to calculate the land footprint of country $r\left(\mathrm{~F}^{\mathrm{r}}\right)$.

$$
\left(\begin{array}{c}
\mathrm{F}^{\mathrm{lr}} \\
\mathrm{F}^{2 \mathrm{r}} \\
\mathrm{F}^{3 \mathrm{r}} \\
\vdots \\
\mathrm{F}^{\mathrm{mr}}
\end{array}\right)=\left(\begin{array}{ccccc}
\hat{\mathrm{S}}^{1} & 0 & 0 & \cdots & 0 \\
0 & \hat{\mathrm{S}}^{2} & 0 & \cdots & 0 \\
0 & 0 & \hat{\mathrm{S}}^{3} & \cdots & 0 \\
\vdots & \vdots & \vdots & \ddots & \vdots \\
0 & 0 & 0 & \cdots & \hat{\mathrm{S}}^{\mathrm{m}}
\end{array}\right)\left\{\left(\begin{array}{ccccc}
\mathrm{I} & 0 & 0 & \cdots & 0 \\
0 & \mathrm{I} & 0 & \cdots & 0 \\
0 & 0 & \mathrm{I} & \cdots & 0 \\
\vdots & \vdots & \vdots & \ddots & \vdots \\
0 & 0 & 0 & \cdots & \mathrm{I}
\end{array}\right)-\left(\begin{array}{ccccc}
\mathrm{A}^{11} & \mathrm{~A}^{12} & \mathrm{~A}^{13} & \cdots & \mathrm{A}^{\mathrm{Im}} \\
\mathrm{A}^{21} & \mathrm{~A}^{22} & \mathrm{~A}^{23} & \cdots & \mathrm{A}^{2 \mathrm{~m}} \\
\mathrm{~A}^{31} & \mathrm{~A}^{32} & \mathrm{~A}^{33} & \cdots & \mathrm{A}^{3 \mathrm{~m}} \\
\vdots & \vdots & \vdots & \ddots & \vdots \\
\mathrm{A}^{\mathrm{m} 1} & \mathrm{~A}^{\mathrm{m} 2} & \mathrm{~A}^{\mathrm{m} 3} & \cdots & \mathrm{A}^{\mathrm{mm}}
\end{array}\right)\right\}^{-1}\left(\begin{array}{c}
\mathrm{y}^{\mathrm{lr}} \\
\mathrm{y}^{2 \mathrm{r}} \\
\mathrm{y}^{3 \mathrm{r}} \\
\vdots \\
\mathrm{y}^{\mathrm{mr}}
\end{array}\right)
$$

Where, $F^{m r}$ (a vector) represents resource consumption in region $\mathrm{r}$ extracted from region $\mathrm{m}$. Country $r$ 's footprint can be represented by the sum of all elements in vectors $F^{1 r}$ to $F^{m r}$. In addition, the diagonal matrix $\widehat{S}^{\mathrm{m}}$ represents the domestic sectoral environmental coefficients for different sectors in region $m$. 
The most recent MRIO database EXIOBASE v3.4, which is publicly available and uses year 2011 as the base year, is employed in this study. In total, 200 products and 163 sectors from 44 countries and 5 continental rest regions are covered in this database. Also, many parameters, including direct requirement coefficients $A$ (in Euros per Euro), final demand $y$ (in Million Euros) and land use coefficients $\hat{S}$ (in square kilometers per Million Euros) are also provided by this database.

\subsection{Cluster analysis}

Cluster analysis is employed to identify China's key trade interrelations within the global land footprint network. The cluster supports the idea that nodes within the same cluster have more dense links than the nodes outside this cluster (Blondel et al., 2008; Gao et al., 2015). According to our previous studies, a two phased cluster analysis based on undirected networks is applied for this study (Tian et al., 2018b).

Equation (4) presents the weighted undirected network:

$$
Q=\frac{1}{2 n} \sum_{i} \sum_{j}\left(n_{i j}-\frac{n_{i} n_{j}}{2 n}\right) \partial\left(E_{i}, E_{j}\right)
$$

Where the weight of the edge between $i$ and $j$ is shown by $n_{i j} . n_{i}$ and $n_{j}$ are node strengths of $i$ and $j$ respectively; $n_{i}=\sum_{j} n_{i j}$ and $n_{j}=\sum_{i} n_{i j}$ represent the sum of the weights of the edges of the studied country. Country $i$ is located in cluster $E_{i}$, and country $j$ is located in cluster $E_{j}$. The $\delta$-function $\delta(a, b)$ is 1 if $a=b$; otherwise the $\delta$-function $\delta(a, b)$ is 0 , and $2 n=\sum_{i} \sum_{j} n_{i j}$.

The cluster analysis is conducted in two phases. In the first phase, the location of one node mainly depends on the feature of the gain of modularity $\Delta Q$, which is shown in equation (5). For instance, if the value of $\Delta Q$ is positive, then node $i$ places in the new cluster; if not, node $i$ stays in its original cluster. In the second phase, a new network is formed based on the results from the first phase. The two phases are iterated until there are no more changes and the maximum modularity is achieved.

$\Delta Q=\left[\frac{\sum_{i n}+k_{i, i n}}{2 g}-\left(\frac{\sum_{t o t}+k_{i}}{2 g}\right)^{2}\right]-\left[\frac{\Sigma_{i n}}{2 g}-\left(\frac{\Sigma_{t o t}}{2 g}\right)^{2}-\left(\frac{k_{i}}{2 g}\right)^{2}\right]$

Where $\Sigma_{\text {in }}$ represents the sum of the weights of the links within community (E), $\Sigma_{\text {tot }}$ represents the sum of the weights of the links incident to nodes in community (E), $k_{i}$ represents the sum of the weights of node $i, k_{i, \text { in }}$ represents the sum of the weights from $i$ to nodes in community (E), and $g$ represents the sum of the weights of all the links within the network.

\subsection{Index decomposition analysis}

Decomposition analysis has been widely applied to uncover the driving factors that determine changes of energy and material consumption, carbon emissions, labor demand, and land use in a process or in an economy (Ang and Zhang, 2000; Cialani, 2007; Hoffren et al., 2000; Jungnitz, 2008; Tian et al., 2015; Tian et al., 2016; Weinzettel and Kovanda, 2011; Wu et al., 2016). Several decomposition analysis methods exist with different advantages. Among these methods, the Logarithmic Mean Divisia Index (LMDI) method has an advantage of the flexibility of decomposition 
index and can replace a zero value by a small positive number, thus, achieving satisfactory decomposition results (Ang et al., 1998; Ang, 2004; Ang and Xu, 2013). Consequently, this method is used in the field of resources consumption and environmental emissions at the national, provincial and industrial levels (Ang and Zhang, 2000; Cialani, 2007; Hoffren et al., 2000; Jungnitz, 2008; Tian et al., 2015; Tian et al., 2016; Wu et al., 2016). Based upon these advantages, the Logarithmic Mean Divisia Index (LMDI) method was chosen in this study to uncover the driving forces of changes in China's land consumption and China's virtual land trade during the phases of 1995-2000, 2000-2005, 2005-2010, and 2010-2015. In this study, the decomposition analysis was split into three parts: (I) China's consumption of domestic land; (II) China's consumption of imported land; (III) China's export of virtual land. In order to eliminate the effects of inflation of monetary items, we deflated all the prices to the 2015 year level.

\section{(I) China's consumption of domestic land}

Equation (6) shows how to calculate the changes in the demand for China's domestic land resources induced by China's domestic consumption $\left(\Delta \mathrm{LF}_{\mathrm{D}}\right)$.

$\Delta L F_{D}=L F^{R_{-}} L F^{0}=\Delta L F_{P}+\Delta L F_{A F}+\Delta L F_{C I}$

Where, $R$ and 0 represent the last and the first study year, respectively. $\Delta L F_{P}$ represents the scale factor showing the contribution of population; $\triangle L F_{A F}$ represents the affluence factor showing the contribution of the level of consumption; $\Delta L F_{C I}$ represents the technology factor showing the influence of land use intensity change. Equation (7) shows how to conduct the decomposition analysis is for China's consumption of domestic land:

$L F_{D}=\sum_{i} P \times \frac{C}{P} \times \frac{L F_{D}}{C}=\sum_{i} P \times S_{i} \times T_{i}$

Where $P$ represents the total population and refers to the scale factor; $C$ represents the final consumption; $S_{i}=C / P$ represents the affluence factor $\Delta L F_{A F} ; T_{i}=L F_{D} / C$ represents the technology factor $\Delta L F_{C I}$.

Equations (8) to (10) show how to quantify these three drivers for China's consumption of domestic land.

$\Delta L F_{P}=\sum_{i} \frac{L F_{i}^{R}-L F_{i}^{0}}{\ln L F_{i}^{R}-\ln L F_{i}^{0}} \ln \left(\frac{P^{R}}{P^{0}}\right)$

$\Delta L F_{A F}=\sum_{i} \frac{L F_{i}^{R}-L F_{i}^{0}}{\ln L F_{i}^{R}-\ln L F_{i}^{0}} \ln \left(\frac{S_{i}^{R}}{S_{i}^{0}}\right)$

$\Delta L F_{C I}=\sum_{i} \frac{L F_{i}^{R}-L F_{i}^{0}}{\ln L F_{i}^{R}-\ln L F_{i}^{0}} \ln \left(\frac{T_{i}^{R}}{T_{i}^{0}}\right)$

\section{(II) China's consumption of imported land}

Equation (11) shows how to calculate the changes in the consumption of foreign land induced by China's final demand $\left(\Delta \mathrm{LF}_{\mathrm{Im}}\right)$.

$\Delta L F_{\text {Im }}=L F^{R}-L F^{0}=\Delta L F_{G}+\Delta L F_{D I}+\Delta L F_{I I}$

Where, $R$ and 0 represent the last study year and the first study year, respectively. $\Delta L F_{G}$ represents the scale factor showing the contribution of GDP; $\Delta L F_{D I}$ represents 
the import trade dependence; $\Delta L F_{I I}$ represents the technology factor showing the land use intensity change. Equation (12) shows how to conduct the decomposition analysis is for China's consumption of imported land:

$L F_{I m}=\sum_{i} G \times \frac{I T}{G} \times \frac{L F_{I L}}{I T}=\sum_{i} G \times M_{i} \times N_{i}$

Where $G$ represents the GDP showing the economic scale of China and refers to the scale factor; IT represents the total import trade volume of China; $M_{i}=I T / G$ represents the dependence of China's consumption on imports, the $\Delta L F_{D I}$ factor represents the degree of openness of China's market for imports; $N_{i}=L F_{I L} / I T$ represents the land use intensity of imports.

Equations (13) to (15) show how to quantify these three drivers for China's consumption of imported land.

$\Delta L F_{G}=\sum_{i} \frac{L F_{i}^{R}-L F_{i}^{0}}{\ln L F_{i}^{R}-\ln L F_{i}^{0}} \ln \left(\frac{G^{R}}{G^{0}}\right)$

$\Delta L F_{D I}=\sum_{i} \frac{L F_{i}^{R}-L F_{i}^{0}}{\ln L F_{i}^{R}-\ln L F_{i}^{0}} \ln \left(\frac{M_{i}^{R}}{M_{i}^{0}}\right)$

$\Delta L F_{I I}=\sum_{i} \frac{L F_{i}^{R}-L F_{i}^{0}}{\ln L F_{i}^{R}-\ln L F_{i}^{0}} \ln \left(\frac{N_{i}^{R}}{N_{i}^{0}}\right)$

\section{(III) China's export of virtual land}

Equation (16) shows how to calculate the changes in China's land use induced by China's trade partners' final demand $\left(\Delta \mathrm{LF}_{\mathrm{Ex}}\right)$.

$\Delta L F_{E x}=L F^{R}-L F^{0}=\Delta L F_{G}+\Delta L F_{D E}+\Delta L F_{E I}$

Where, $R$ and 0 represent the last study year and the first study year, respectively. $\Delta L F_{G}$ is the scale factor showing the contribution of GDP; $\triangle L F_{D E}$ represents the structure factor showing the contribution of exports to the GDP; $\Delta L F_{E I}$ represents the technology factor showing the land use intensity change. Equation (17) shows how to conduct the decomposition analysis for China's export of virtual land:

$L F_{E x}=\sum_{i} G \times \frac{E T}{G} \times \frac{L F_{E L}}{E T}=\sum_{i} G \times W_{i} \times V_{i}$

Where $G$ represents the GDP showing the economic scale of China; ET represents the total export trade volume of China; $W_{i}=E T / G$ represents the share of China's export trade in GDP; $\mathrm{V}_{i}=L F_{E L} / E T$ represents land use intensity of exports.

Equations (18) to (20) show how to quantify these three drivers for China's export of virtual land.

$\Delta L F_{G}=\sum_{i} \frac{L F_{i}^{R}-L F_{i}^{0}}{\ln L F_{i}^{R}-\ln L F_{i}^{0}} \ln \left(\frac{G^{R}}{G^{0}}\right)$

$\Delta L F_{D E}=\sum_{i} \frac{L F_{i}^{R}-L F_{i}^{0}}{\ln L F_{i}^{R}-\ln L F_{i}^{0}} \ln \left(\frac{W_{i}^{R}}{W_{i}^{0}}\right)$

$\Delta L F_{E I}=\sum_{i} \frac{L F_{i}^{R}-L F_{i}^{0}}{\ln L F_{i}^{R}-\ln L F_{i}^{0}} \ln \left(\frac{V_{i}^{R}}{V_{i}^{0}}\right)$

\section{Results}

\subsection{The trends of China's LF}


Figure 1 shows the main trends of China's LF from 1995 to 2015. While global land use decreased by almost $7.1 \%$ from $6.1 \mathrm{E}+07 \mathrm{~km}^{2}$ in 1995 to $5.6 \mathrm{E}+07 \mathrm{~km}^{2}$ in 2015 , China's LF shows an increasing trend in the given period, rising by $66.5 \%$ from 1995 to 2015. China's LF, including cropland, forests and grassland, accounts for $8.8 \%, 9.8 \%$, $10.0 \%, 12.8 \%$ and $15.7 \%$ of the global LF for the years 1995, 2000, 2005, 2010 and 2015 , respectively. Among the three land types, China's grassland consumption holds the largest share from 1995 to 2000, while forests instead became the largest fraction since 2005.

Overall, China's demand for land is mainly met by domestic sources at an average of $69.2 \%$, thus only $30.8 \%$ of its LF originate from foreign countries' land resources. While China's domestic LF shows a declining trend from $4.7 \mathrm{E}+06 \mathrm{~km}^{2}$ in 1995 to $4.3 \mathrm{E}+06 \mathrm{~km}^{2}$ in 2015 , its foreign LF which supplied China's final demand significantly increased from $5.8 \mathrm{E}+05 \mathrm{~km}^{2}$ in 1995 to $4.6 \mathrm{E}+06 \mathrm{~km}^{2}$ in 2015 , indicating that China's increasing demand cannot be satisfied by expanding domestic land use anymore, but has to be met increasingly by imports. The same general trends can be observed for all three land use types. 
(a)

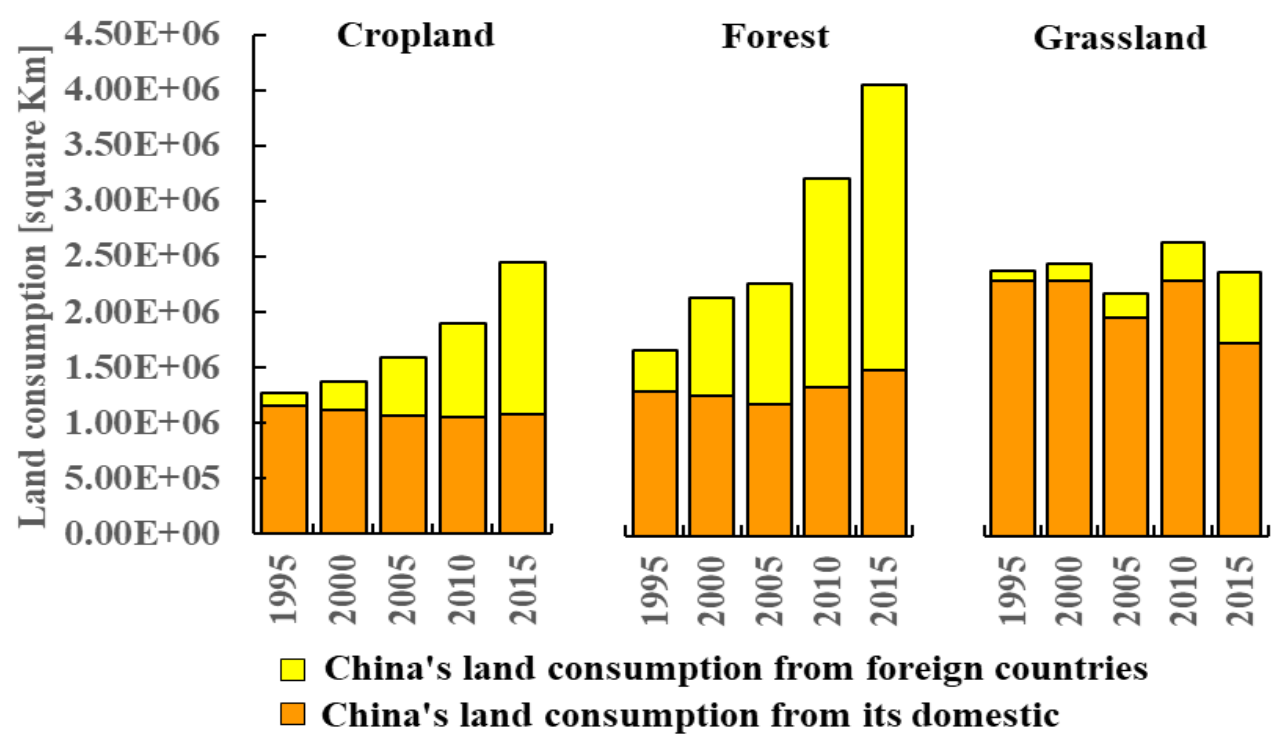

(b)

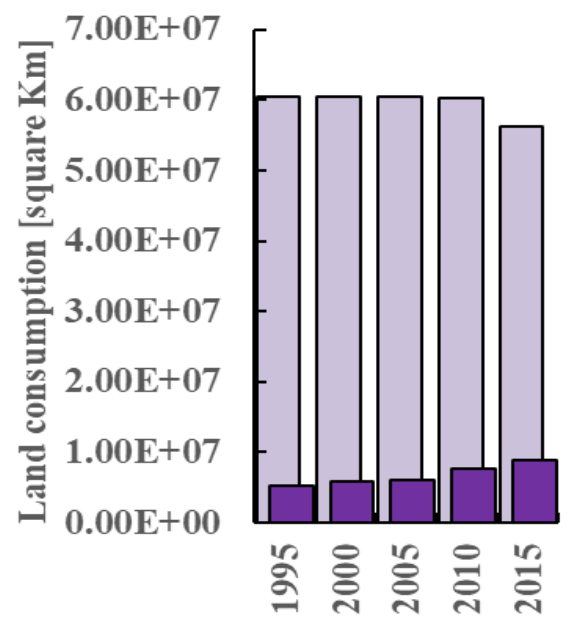

(c)

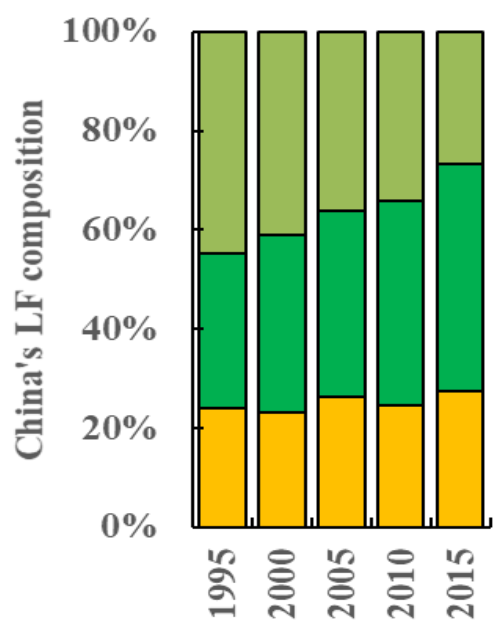

$\square$ World's land consumption China's land consumption

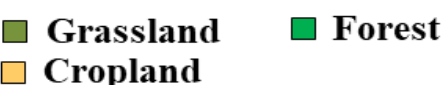

Figure 1 The main trends of China's total LF (a), China's LF contribution to the world's (b) and China's LF composition (c) from 1995 to 2015 (note: in Figure (1-a), China's total land consumption $=$ China's land consumption for its domestic + China's land consumption from foreign countries)

China's LFs at the product level are shown in Table 1. The product structure changed significantly for China's domestic land consumption, which shows how much land China consumes from its own territory. For cropland, the product group 'Vegetables, fruit, nuts' (p01.d) is the largest item from 1995 to 2005, while consumption of 'Food products' (p15.i) has the largest LF from 2010 to 2015. Besides that, 'Construction work' (p45) shows a slightly increasing trend in the given period. For grassland, it can be noted that the diversity of products changed significantly after 2010. 'Cattle' (p01.i) and 'raw milk' (p01.n) caused the biggest LFs from 1995 to 2010, while other products experienced increasing trends from 2010 onwards. For forest land, 'Products of forestry' (p02) and 'Construction work' (p45) are the two top products 

(p36) both increased significantly. The product structure for China's consumption of imported land from foreign countries, in general, is different from China's domestic LFs except for forest. For instance, 'oil seeds' (p01.e) and 'construction work' are the largest land consumption products for cropland; 'construction work' and 'cattle' are the major products for the consumption of grassland.

Table 1 The top five commodities of three specific land consumption

\begin{tabular}{|c|c|c|c|c|c|c|c|c|c|}
\hline \multicolumn{10}{|c|}{ Cropland } \\
\hline \multicolumn{2}{|c|}{1995} & \multicolumn{2}{|c|}{2000} & \multicolumn{2}{|c|}{2005} & \multicolumn{2}{|c|}{2010} & \multicolumn{2}{|c|}{2015} \\
\hline D & I & D & I & D & I & D & I & $\mathrm{D}$ & I \\
\hline p01.d & $\mathrm{p} 45$ & $\mathrm{p} 01 . \mathrm{d}$ & $\mathrm{p} 45$ & p01.d & p01.e & p15.i & p01.e & $\mathrm{p} 15 . \mathrm{i}$ & p01.e \\
\hline p01.c & p01.e & p01.c & p01.e & p15.i & $\mathrm{p} 45$ & p01.d & $\mathrm{p} 45$ & p01.e & $\mathrm{p} 45$ \\
\hline p01.e & $\mathrm{p} 75$ & p01.e & p01.c & p01.c & p15.i & p01.c & $\mathrm{p} 15 . \mathrm{i}$ & $\mathrm{p} 45$ & p15.i \\
\hline p01.a & p01.c & p15.g & $\mathrm{p} 75$ & p01.e & p75 & $\mathrm{p} 45$ & p85 & p15.g & $\mathrm{p} 85$ \\
\hline $\mathrm{p} 45$ & $\mathrm{p} 55$ & $\mathrm{p} 45$ & $\mathrm{p} 80$ & $\mathrm{p} 45$ & p01.c & p15.g & p15.k & p15.k & p63 \\
\hline \multicolumn{10}{|c|}{ Grassland } \\
\hline \multicolumn{2}{|c|}{1995} & \multicolumn{2}{|c|}{2000} & \multicolumn{2}{|c|}{2005} & \multicolumn{2}{|c|}{2010} & \multicolumn{2}{|c|}{2015} \\
\hline $\mathrm{D}$ & I & $\mathrm{D}$ & I & $\mathrm{D}$ & I & D & I & $\mathrm{D}$ & I \\
\hline $\mathrm{p} 01 . \mathrm{i}$ & $\mathrm{p} 45$ & $\mathrm{p} 01 . \mathrm{i}$ & $\mathrm{p} 45$ & p01.n & p01.i & $\mathrm{p} 01 . \mathrm{i}$ & $\mathrm{p} 01 . \mathrm{i}$ & $\mathrm{p} 01 . \mathrm{i}$ & $\mathrm{p} 01 . \mathrm{i}$ \\
\hline p01.n & p75 & p01.n & p75 & p01.i & $\mathrm{p} 45$ & p01.n & $\mathrm{p} 45$ & p15.a & $\mathrm{p} 45$ \\
\hline p01.1 & $\mathrm{p} 55$ & p01.1 & $\mathrm{p} 55$ & p15.a & $\mathrm{p} 75$ & $\mathrm{p} 01.1$ & $\mathrm{p} 85$ & p01.n & $\mathrm{p} 85$ \\
\hline p15.a & p29 & p15.a & $\mathrm{p} 80$ & p55 & p55 & p15.k & p15.k & $\mathrm{p} 45$ & $\mathrm{p} 15 . \mathrm{k}$ \\
\hline $\mathrm{p} 55$ & $\mathrm{p} 80$ & p55 & $\mathrm{p} 85$ & p01.1 & $\mathrm{p} 80$ & $\mathrm{p} 45$ & p75 & p01.1 & p15.a \\
\hline \multicolumn{10}{|c|}{ Forest } \\
\hline \multicolumn{2}{|c|}{1995} & \multicolumn{2}{|c|}{2000} & \multicolumn{2}{|c|}{2005} & \multicolumn{2}{|c|}{2010} & \multicolumn{2}{|c|}{2015} \\
\hline $\mathrm{D}$ & I & $\mathrm{D}$ & I & $\mathrm{D}$ & I & $\mathrm{D}$ & I & $\mathrm{D}$ & I \\
\hline p02 & p02 & p02 & p02 & p02 & p02 & p02 & p02 & p02 & $\mathrm{p} 45$ \\
\hline $\mathrm{p} 45$ & $\mathrm{p} 45$ & $\mathrm{p} 45$ & $\mathrm{p} 45$ & p45 & $\mathrm{p} 45$ & $\mathrm{p} 45$ & $\mathrm{p} 45$ & $\mathrm{p} 45$ & $\mathrm{p} 85$ \\
\hline p75 & $\mathrm{p} 75$ & p75 & $\mathrm{p} 75$ & p85 & p85 & $\mathrm{p} 85$ & p85 & p85 & p36 \\
\hline p80 & p80 & p85 & p80 & p36 & p75 & p36 & p36 & p36 & p34 \\
\hline p36 & p93 & p80 & p85 & p75 & p80 & p73 & p75 & p34 & p29 \\
\hline
\end{tabular}

(Note: D presents China's domestic LF; I presents China's LF via imported commodities. Meaning of the commodities' code: p01.d- Vegetables, fruit, nuts; p01.c- Cereal grains; p01.e- Oil seeds; p01.a- Paddy rice; p45- Construction work; p75- Public administration and defense services; compulsory social security services; p55- Hotel and restaurant services; p15.g- Processed rice; p80- Education services; p15.i- Food products; p85- Health and social work services; p15.k- Fish products; p63- Supporting and auxiliary transport services; travel agency services; p01.i- Cattle; p01.n- Raw milk; p01.1- Meat animals; p15.a- Products of meat cattle; p29- Machinery and equipment; p02- Products of forestry, logging and related services; p36- Furniture; other manufactured goods; p93- Other services; p73- Research and development services; p34- Motor vehicles, trailers and semi-trailers) 
333 shown in Figure 2 and Table 2. Results show that China's virtual land trade results in 334 net imports ranging from $9.4 \mathrm{E}+04 \mathrm{~km}^{2}$ in 1995 to $3.4 \mathrm{E}+06 \mathrm{~km}^{2}$ in 2015 . During the 335 time series, the USA, Brazil and Canada are the main net virtual cropland contributors 336 to China's final consumption, while China is a net exporter to Japan, Korea, Germany, 337 UK and Italy; for forest areas, Russia and Australia are the main net virtual land suppliers to China, while the USA, Japan and UK are the main importers of virtual forest land from China; for grassland, China mainly imported virtual land from Australia and South Africa, and exported to the USA and Japan.

Figure 2 The net virtual land trade of China from 1995 to 2015 in square kilometers

Table 2 China's top 5 net import and export virtual land trade partners in square kilometers 


\begin{tabular}{|c|c|c|c|c|c|c|}
\hline & \multicolumn{2}{|c|}{ Cropland } & \multicolumn{2}{|c|}{ Forest } & \multicolumn{2}{|c|}{ Grassland } \\
\hline & Net Im & Net Ex & Net Im & Net Ex & Net Im & Net Ex \\
\hline \multirow[t]{5}{*}{1995} & $\mathrm{CA}(1.7 \mathrm{E}+04)$ & $\mathrm{JP}(2.6 \mathrm{E}+04)$ & $\mathrm{RU}(1.1 \mathrm{E}+05)$ & $\mathrm{JP}(1.2 \mathrm{E}+04)$ & $\mathrm{AU}(5.6 \mathrm{E}+03)$ & $\mathrm{US}(5.1 \mathrm{E}+04)$ \\
\hline & $\mathrm{BR}(1.1 \mathrm{E}+04)$ & $\mathrm{KR}(1.2 \mathrm{E}+04)$ & ID $(4.2 \mathrm{E}+04)$ & $\mathrm{US}(5.2 \mathrm{E}+03)$ & & $\mathrm{JP}(2.8 \mathrm{E}+04)$ \\
\hline & $\mathrm{AU}(5.4 \mathrm{E}+03)$ & $\mathrm{DE}(5.7 \mathrm{E}+03)$ & $\mathrm{CA}(6.2 \mathrm{E}+03)$ & $\mathrm{KR}(2.8 \mathrm{E}+03)$ & & $\mathrm{RU}(2.4 \mathrm{E}+04)$ \\
\hline & IN $(2.7 \mathrm{E}+03)$ & $\mathrm{GB}(3.3 \mathrm{E}+03)$ & $\mathrm{AU}(4.1 \mathrm{E}+03)$ & $\mathrm{GB}(1.3 \mathrm{E}+03)$ & & $\mathrm{GB}(7.2 \mathrm{E}+03)$ \\
\hline & PL (9.8E+01) & IT $(3.0 \mathrm{E}+03)$ & $\mathrm{BR}(2.1 \mathrm{E}+03)$ & IT $(9.0 \mathrm{E}+02)$ & & $\mathrm{DE}(6.6 \mathrm{E}+03)$ \\
\hline \multirow[t]{5}{*}{2000} & US (3.9E+04) & $\mathrm{JP}(2.9 \mathrm{E}+04)$ & $\mathrm{RU}(4.1 \mathrm{E}+05)$ & US (5.2E+04) & $\mathrm{AU}(1.7 \mathrm{E}+04)$ & $\mathrm{US}(8.4 \mathrm{E}+04)$ \\
\hline & $\mathrm{BR}(2.5 \mathrm{E}+04)$ & $\mathrm{KR}(1.5 \mathrm{E}+04)$ & ID (9.9E+04) & $\mathrm{JP}(2.2 \mathrm{E}+04)$ & $\mathrm{RU}(2.7 \mathrm{E}+03)$ & $\mathrm{JP}(3.6 \mathrm{E}+04)$ \\
\hline & $\mathrm{AU}(2.5 \mathrm{E}+04)$ & $\mathrm{DE}(9.2 \mathrm{E}+03)$ & $\mathrm{CA}(8.0 \mathrm{E}+03)$ & $\mathrm{GB}(7.0 \mathrm{E}+03)$ & $\mathrm{ZA}(7.7 \mathrm{E}+02)$ & $\mathrm{GB}(1.1 \mathrm{E}+04)$ \\
\hline & $\mathrm{CA}(2.2 \mathrm{E}+04)$ & $\mathrm{GB}(7.6 \mathrm{E}+03)$ & $\mathrm{AU}(7.2 \mathrm{E}+03)$ & $\mathrm{KR}(3.9 \mathrm{E}+03)$ & & $\mathrm{DE}(9.0 \mathrm{E}+03)$ \\
\hline & $\mathrm{RU}(5.1 \mathrm{E}+03)$ & IT $(4.1 \mathrm{E}+03)$ & $\mathrm{BR}(7.1 \mathrm{E}+03)$ & IT $(3.7 \mathrm{E}+03)$ & & $\mathrm{FR}(6.7 \mathrm{E}+03)$ \\
\hline \multirow[t]{5}{*}{2005} & US (1.1E+05) & $\mathrm{JP}(2.9 \mathrm{E}+04)$ & $\mathrm{RU}(7.6 \mathrm{E}+05)$ & US (1.2E+05) & $\mathrm{AU}(2.9 \mathrm{E}+04)$ & $\mathrm{US}(1.7 \mathrm{E}+05)$ \\
\hline & $\mathrm{BR}(9.1 \mathrm{E}+04)$ & $\mathrm{KR}(1.6 \mathrm{E}+04)$ & ID $(3.9 \mathrm{E}+04)$ & $\mathrm{JP}(3.5 \mathrm{E}+04)$ & $\mathrm{ZA}(7.9 \mathrm{E}+01)$ & $\mathrm{JP}(6.7 \mathrm{E}+04)$ \\
\hline & $\mathrm{CA}(2.5 \mathrm{E}+04)$ & $\mathrm{DE}(1.2 \mathrm{E}+04)$ & $\mathrm{BR}(3.0 \mathrm{E}+04)$ & $\mathrm{GB}(1.8 \mathrm{E}+04)$ & & $\mathrm{GB}(3.6 \mathrm{E}+04)$ \\
\hline & $\mathrm{AU}(2.0 \mathrm{E}+04)$ & $\mathrm{GB}(1.0 \mathrm{E}+04)$ & $\mathrm{AU}(1.3 \mathrm{E}+04)$ & $\mathrm{DE}(1.3 \mathrm{E}+04)$ & & $\mathrm{DE}(2.7 \mathrm{E}+04)$ \\
\hline & ID $(1.5 \mathrm{E}+04)$ & IT $(5.4 \mathrm{E}+03)$ & $\mathrm{CA}(2.7 \mathrm{E}+03)$ & $\mathrm{FR}(1.0 \mathrm{E}+04)$ & & $\mathrm{FR}(2.1 \mathrm{E}+04)$ \\
\hline \multirow[t]{5}{*}{2010} & $\mathrm{US}(2.1 \mathrm{E}+05)$ & JP (1.7E+04) & $\mathrm{RU}(8.2 \mathrm{E}+05)$ & JP (2.7E+04) & $\mathrm{AU}(6.6 \mathrm{E}+04)$ & $\mathrm{US}(6.0 \mathrm{E}+04)$ \\
\hline & $\mathrm{BR}(1.5 \mathrm{E}+05)$ & $\mathrm{DE}(9.0 \mathrm{E}+03)$ & $\mathrm{CA}(8.0 \mathrm{E}+04)$ & US $(1.4 \mathrm{E}+04)$ & $\mathrm{ZA}(3.5 \mathrm{E}+03)$ & $\mathrm{JP}(2.7 \mathrm{E}+04)$ \\
\hline & $\mathrm{CA}(3.2 \mathrm{E}+04)$ & $\mathrm{KR}(8.8 \mathrm{E}+03)$ & $\mathrm{AU}(7.5 \mathrm{E}+04)$ & $\mathrm{GB}(1.2 \mathrm{E}+04)$ & $\mathrm{BR}(1.4 \mathrm{E}+03)$ & $\mathrm{DE}(1.4 \mathrm{E}+04)$ \\
\hline & $\mathrm{AU}(2.5 \mathrm{E}+04)$ & $\mathrm{GB}(6.8 \mathrm{E}+03)$ & $\mathrm{BR}(2.3 \mathrm{E}+04)$ & $\mathrm{DE}(1.1 \mathrm{E}+04)$ & $\mathrm{RU}(2.6 \mathrm{E}+02)$ & $\mathrm{GB}(1.1 \mathrm{E}+04)$ \\
\hline & ID $(2.3 \mathrm{E}+04)$ & IT $(4.1 \mathrm{E}+03)$ & ID $(2.3 \mathrm{E}+04)$ & IN $(7.8 \mathrm{E}+03)$ & & $\mathrm{FR}(7.9 \mathrm{E}+03)$ \\
\hline \multirow[t]{5}{*}{2015} & $\mathrm{US}(5.0 \mathrm{E}+05)$ & $\mathrm{JP}(1.4 \mathrm{E}+04)$ & $\mathrm{RU}(8.3 \mathrm{E}+05)$ & US (4.7E+04) & $\mathrm{AU}(1.5 \mathrm{E}+05)$ & $\mathrm{US}(5.8 \mathrm{E}+04)$ \\
\hline & $\mathrm{BR}(2.5 \mathrm{E}+05)$ & $\mathrm{KR}(1.1 \mathrm{E}+04)$ & $\mathrm{AU}(2.3 \mathrm{E}+05)$ & $\mathrm{JP}(4.4 \mathrm{E}+04)$ & $\mathrm{ZA}(1.0 \mathrm{E}+04)$ & $\mathrm{JP}(2.5 \mathrm{E}+04)$ \\
\hline & $\mathrm{CA}(6.8 \mathrm{E}+04)$ & $\mathrm{DE}(7.1 \mathrm{E}+03)$ & $\mathrm{CA}(1.9 \mathrm{E}+05)$ & $\mathrm{GB}(2.4 \mathrm{E}+04)$ & $\mathrm{BR}(7.0 \mathrm{E}+03)$ & $\mathrm{DE}(1.5 \mathrm{E}+04)$ \\
\hline & $\mathrm{AU}(4.6 \mathrm{E}+04)$ & $\mathrm{GB}(6.2 \mathrm{E}+03)$ & $\mathrm{BR}(6.0 \mathrm{E}+04)$ & $\mathrm{IN}(2.1 \mathrm{E}+04)$ & $\mathrm{RU}(4.1 \mathrm{E}+03)$ & $\mathrm{GB}(1.1 \mathrm{E}+04)$ \\
\hline & $\mathrm{RU}(2.6 \mathrm{E}+04)$ & IT $(2.3 \mathrm{E}+03)$ & ID $(3.0 \mathrm{E}+04)$ & $\mathrm{DE}(1.9 \mathrm{E}+04)$ & & $\mathrm{FR}(9.8 \mathrm{E}+03)$ \\
\hline
\end{tabular}

Note: Im = imports; Ex = exports; CA (Canada), BR (Brazil), AU (Australia), IN (India), PL (Poland), US (United States), RU (Russia), ID (Indonesia), JP (Japan), KR (Korea), DE (Germany), GB (United Kingdom), IT (Italy), ZA (South Africa), FR (France).

\subsection{The features of China's virtual land (VL) network}

The evolutions of specific VL clusters are shown in Figure 3. The network characteristics are different for the three land classification types. As mentioned in the methods section, the VL network reveals hidden relationship between countries. The VL trading relationship between China and its trade partners is close with each other if they are located in the same cluster. For the cropland network, it shows that the cluster structure has been almost stable since 2000. The analysis reveals that the network has three clusters. The EU countries belong to the same cluster during the whole period, indicating close trade relations among the EU countries. The EU's Common Agricultural Policy played a key role in forming this pattern, as it boosted trade between 
EU countries while establishing barriers for extra-EU trade in the form of diverse tariffs on products (Matthews et al., 2017). We also find that the USA, Mexico and Canada are always located in the same cluster, probably due to the North American Free Trade Agreement (Dalin et al., 2012). For China, tight relationships can be observed with Australia, Japan, Brazil and Korea. Good diplomatic relationships and the supplydemand relationship may cause these countries belonging to the same cluster. For instance, under the long term free trade relationship between China and Australia since 2005, China received more virtual land through imported more agricultural products from Australia (Tian et al., 2018b). The proximity and complementary resource endowments may be major reasons for the long-term trade relationships between Japan and China.

Looking at the forest network we could find four clusters in 1995, but only two clusters from 2000 onwards. An interesting characteristic of the cluster is that most countries belong to the same cluster as China except Canada, USA and Mexico. Globalization drives the international division of labor also in the forestry and wood industry. China reportedly played a key role in international forest trade with distinctly high growth of domestic consumption, imports and exports. China imported primary forest resources from more than 80 countries and then manufactured them exporting to most developed countries for consumption ${ }^{1}$.

For the grassland network, the cluster structure is stable with two clusters during the whole period. The increasing demand of meat products in the world accelerated the trade between countries with different resource endowments. China shows tight VL networks with Canada, USA, Mexico, Australia, Korea and Japan.

\subsection{The driving forces of China's virtual land consumption}

In order to explore the driving factors of China's land consumption changes in-depth, three types of China's land consumption are identified as mentioned in the methods section above. The results are shown in Figure 4. For the consumption of domestic land resources induced by China's final demand, the total contribution of the three factors (population, affluence, land use intensity) in each time step shows negative effects except for the 2005-2010 period, mainly due to the affluence effect. Changes in land use intensity are the biggest decreasing factor for China's land consumption in all periods except for 2005-2010, thereby playing a key role in reducing China's land consumption. Affluence is the largest driver of increasing land consumption throughout the entire investigated period, indicating that land consumption could increase in the future due to a rising middle class in China. Compared to these factors, population changes have only a minor driving effect over the given time.

For China's consumption of land resources from foreign countries (China's virtual land imports), the total contribution of the three factors (economic scale, import dependency, land use intensity) is positive in each time step mainly due to the economic scale effect, which is the biggest driving force of LF changes over the whole time period. The effects of changes in import dependency and land use intensity are unstable during the whole period. For instance, the dependence factor contributes to increasing LF

1 http://www.iisd.org 
during the periods $1995-2000$ and 2000-2005, while it shows negative contributions during periods 2005-2010 and 2010-2015. Although these two factors show unstable effects, the results indicate that they have great potential to reduce land consumption.

The tremendous increase in China's virtual land exports during all stages except 2005-2010 are mainly explained by the economic scale of the Chinese economy. Changes in the export share had only a minor positive effect. Land use intensity changes had a negative effect throughout the whole time period except for the stage of 20102015 which, however, could curb VL exports only slightly.
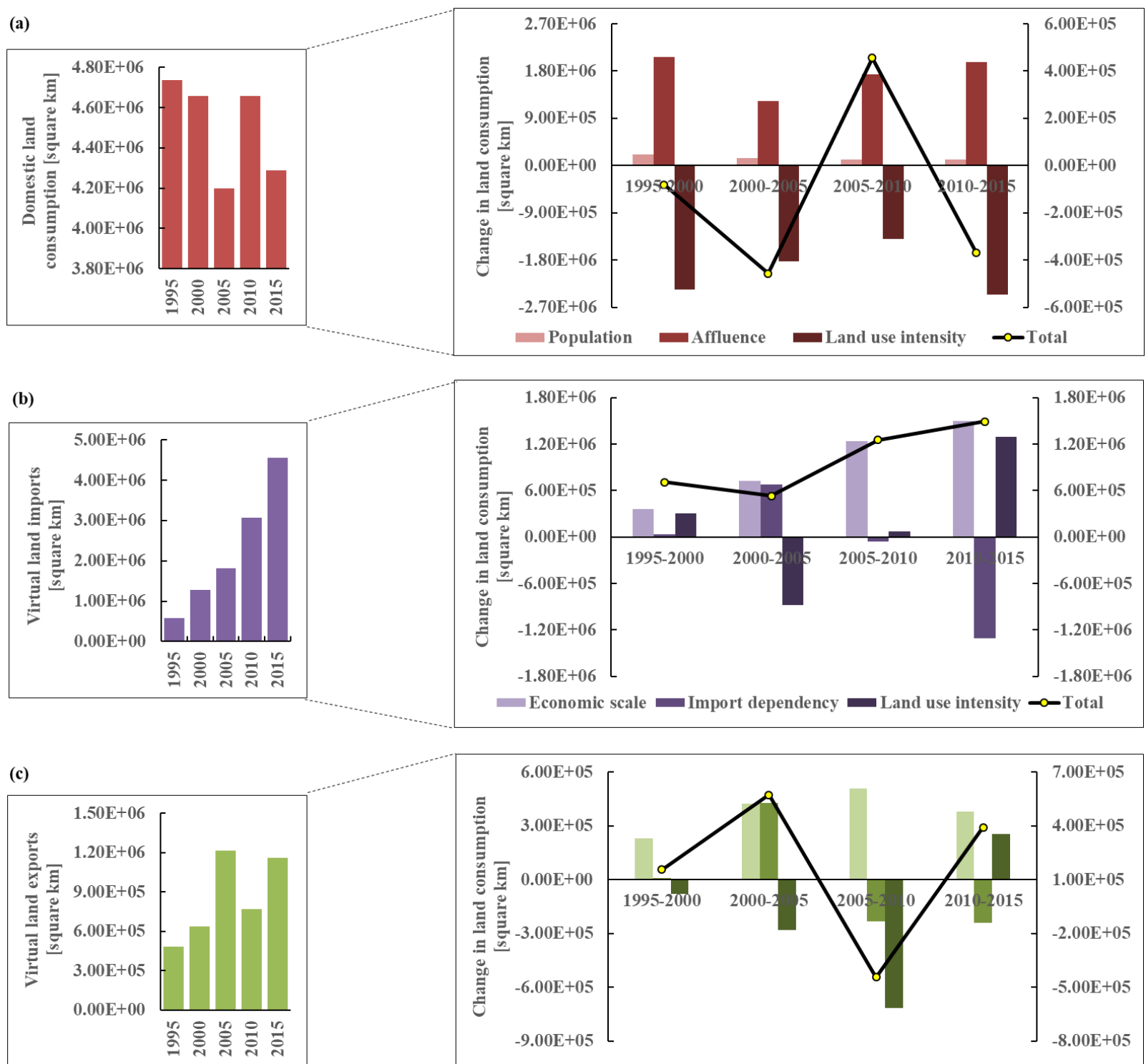

Figure 4. The driving forces of changes of (a) China's domestic land consumption, (b) China's virtual land imports, and (c) China's virtual land exports. The left scales in each plot refer to the bars, while the right scales refer to the lines.

\section{Policy implications}

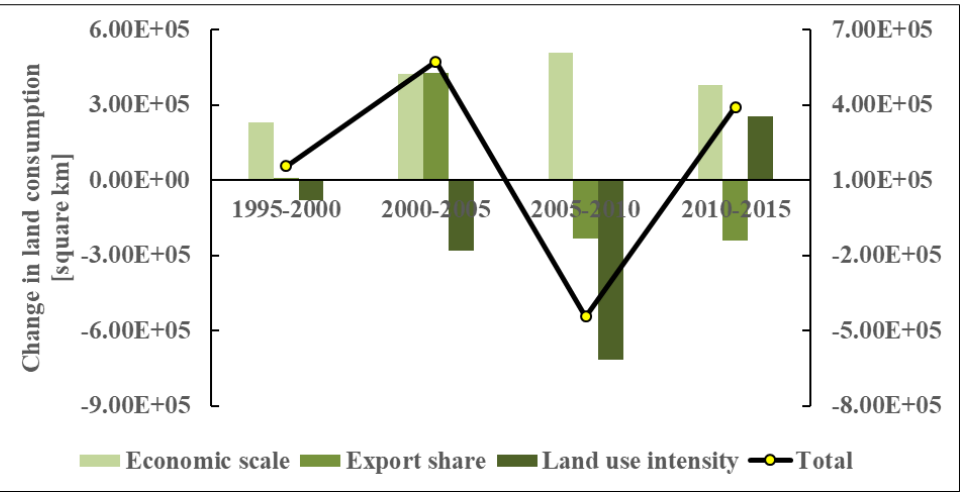


This study investigates China's land footprint (LF), which presents the amount of land resources directly and indirectly used to produce goods and services for China's final consumption in the given period. It includes the land consumption of domestic and imported virtual land (VL) from China's foreign trade partners. Totally, China's LF experienced an increasing trend in the given period, increased by $66.5 \%$ from 1995 to 2015.

The structure of China's LF has been changed significantly since 2005. The forest LF has become the largest footprint, fueled by China's growing economy and unprecedented urbanization associated with increasing demand for forest products (Zhang et al., 2017). For instance, China's timber market has been one of the largest in the world due to the increment of China's urban population (Peng, 2011).

At the product level we see that the consumption of primary products causes the largest imports the product composition is more diverse and changed over time. The most important change is the increasing LF of products related to construction work, which is related to rapid urbanization in China (Han and Chen, 2018).

Fast land conversion for non-agricultural use has become the main feature of China's urbanization. Generally, industrial land and residential land are the two major sources of non-agricultural land conversion (Liu et al., 2014). According to land use statistics, the total quantity of construction land conversely changed compared with the change in the total quantity of cultivated land from 2009 to 2014, that is, construction increased by $311.46 \mathrm{E}+10^{4} \mathrm{hm}^{2}$ during this period (Ministry of Land and Resources, 2005-2010).

China's urbanization causes detrimental effects, such as rural and urban diseases. Rural diseases include population outflow, abandoned land, industry recession, and environmental pollution, while urban diseases include traffic congestion, air pollution, property bubbles, high living costs, and wastes, due to an overexpansion of urban areas (Liu et al., 2014).

In order to respond these problems, the Chinese government released ecological civilization policy to balance the relationship between socio-economic development and land use. In line with Liu et al. (2018); Bleischwitz et al. (2018) and the SDGs 11 and 15 we propose to explore goals that would unify economic, social and environmental benefits of land use and facilitate a more inclusive sustainable growth. Land consolidation could be considered a useful tool for sustainable development of vacant and waste land and improving the quality of land. A China-specific series of land consolidation projects could address industry agglomerations, environmental governance and optimal land allocation. In addition, urbanization should be better coordinated and aligned with agricultural modernization and new rural construction policies via appropriate planning processes (Liu and $\mathrm{Li}, 2017$ ). 
The transformation of land use also brings several challenges for rural development and needs special consideration. For example, irrational urbanization led to inefficient use of land and decreased agriculture production (Bai et al., 2014). Also, farmland large amount of rural population moved to cities for better jobs and life, leading to abandoned farmland (Yang et al., 2018). This requires the Chinese government to take various efforts. Preferable policies should be prepared to attract more investment in rural areas so that rural residents can easily find job opportunities, such as preferable tax rates, financial subsidies, and rural planning. Capacity-building measures should also be al., 2019). In addition, technology transfer should be supported so that rural regions can revitalize their economy by applying innovative technologies. Finally, it is critical for the local governments to invest more funds on recovering the functions of natural ecosystems and constructing more infrastructure to improve the rural life (Gao et al., 2017; Li et al., 2018)

From a trade perspective, obviously, China's expanding demand was met by increasing imports rather than domestic production. China increased significantly its net imports of virtual land from its international trade partners during the given time period. Our results are consistent with previous studies (Ali et al., 2016; Han and Chen, 2018; Qiang et al., 2013). We show that China's increasing population and changing diets, together with limited domestic agricultural production capacities, resulted in significantly increasing imports. In general, imported virtual land is mainly embodied in primary and food products. For China's virtual land trade network for cropland and grassland it can be noted that China maintains stable relationships with most countries. However, management practices and policies in these countries have an influence on China's land consumption. Compared to grassland and cropland, China's forest virtual land trade network appears to be more stable, particularly since 2000. China keeps tight trade relations with more countries related to forest compared to its international relations related to the other land use categories, indicating a reduced supply risk for forestry products. In addition, it can be noted the VL network is also shaped by trade agreements, diplomatic relations, a supply-demand relationship and also the resource endowment of a country. The land use efficiency of the trade network, on the other side, is not only helping China to mitigate effects of a potential crisis on the international market, but also to reduce China's virtual land consumption, i.e., the application of advanced land use techniques and management practices of China's trade partners helps minimizing China's VL imports and land consumption.

As for the driving forces of China's land consumption, the results show that affluence and land use intensity are the major driving factors for China's domestic consumption. Consumers' income has risen greatly accompanied by changes in lifestyles, consumption patterns and diets. Therefore, the demand for land related products increased (Jan et al., 2013; Liu et al., 2018; Weinzettel and Kovanda, 2011). In order to curb China's land consumption abroad and any related negative socioecological consequences, green consumption should be further promoted in China. Government should initiate capacity-building efforts in order to improve local residents' 
environmental awareness for impacts generated elsewhere. The efforts toward a low carbon society and a circular economy should be useful in a promotion of 'footprints' and life-cycle thinking (Mont and Bleischwitz 2007). Feasible activities could include interactive workshops, newsletters, TV/radio promotions, and outside advertisements (Qian et al., 2018). Also, preferable policies, such as economic instruments and labels, should address green consumption in such perspective, inter alia lower tax rates on sustainable products, and higher ones on resource-intensive luxury products (Geng et al., 2013; Zhu et al., 2013). In addition, charity activities on re-use could be supported, so that textiles could have a second life for poor rural residents (Tian et al., 2015). On a more strategic level, reducing food waste is in line with the support for a circular economy in China, and addressing increasingly livestock-based urban dietary patterns would be very relevant (Geng et al., 2019). From the industrial perspective, it is critical to improve land use efficiency by measures such as adjusting the structure of agricultural production and imports in a way minimizing land use, promoting efficient agricultural technologies, and protecting agricultural land against conversion into urban spaces and the built environment (Liu et al., 2018). In an international dimension, our results indicate a growing import dependence for China, which suggests more international cooperation to decrease land consumption, e.g., by technology transfer and capacity building for sustainable land use, by concluding trade agreements especially focused on sustainable agriculture and land use, and more integrated planning across the international supply chain networks (Biggs et al., 2015; Tomei et al., 2017).

\section{Conclusions}

China has been undergoing profound economic and social transformation which drives China's land consumption. This study identifies the evolution and characteristics of China's footprint and virtual land trade from 1995 to 2015. The main novel contributions of this study are: (1) identifying China's land footprint trends for cropland, forest and grassland at the national and product levels; (2) exploring the properties of China's virtual land trade networks; and (3) revealing the driving forces of changes in China's land consumption. China's land footprint shows increasing trends, rising by $66.5 \%$ from 1995 to 2015. China's grassland consumption is the largest land consumption category from 1995 to 2000, while forest consumption has become the largest one since $2005 \mathrm{~s}$. Furthermore, China's land footprint was mainly sourced from domestic land resources in 1995 at an average rate of $89.1 \%$, while $10.9 \%$ comes from foreign countries. These shares changed to $48.5 \%$ and $51.5 \%$, respectively, in 2015 . China's virtual land trade balance presents net imports increasing from $9.4 \mathrm{E}+04 \mathrm{~km}^{2}$ in 1995 to $3.4 \mathrm{E}+06 \mathrm{~km}^{2}$ in 2015 . China keeps tight VL exchange relationships with Australia, Japan, Brazil and Korea for the case of cropland, and with Canada, USA, Mexico, Australia, Korea and Japan for the case of grassland. In addition, our analysis reveals that affluence and land use intensity are the major driving factors for China's domestic consumption. Rising affluence promoted an increase of land consumption, e.g. through timber imports for construction and consumer products, while changes in the land use efficiency had a reverse effect on the country's land footprint. 
The dynamic economic development of China along with changing consumption patterns lead to major sustainability challenge both for China and for main trade partners. Simply because of the country's mere scale, annual growth rates of $3.3 \%$ for its land consumption on average through the analyzed time period pose a serious threat for sustainable development at a global level. This challenge needs to be addressed by the country itself, e.g. by promoting green consumption behaviors and supply chains, but shouldn't be neglected by the international community either. Global cooperation, capacity building and technology transfer could provide essential support for and from China on its way toward a sustainable resource consumption, not only for the case of land use.

Although our current study presents the historical trend of China's land consumption during the past 20 years, there are still some limitations which could be improved in the future. Further research could explore more relevant driving forces and causalities. Also, indicators at the social level should be explored, i.e. affordability of products should be aligned with sustainability along supply chains and fair trade for producers. In addition, governance mechanisms for international partnerships on sustainable land use and consumption should be explored as well. 


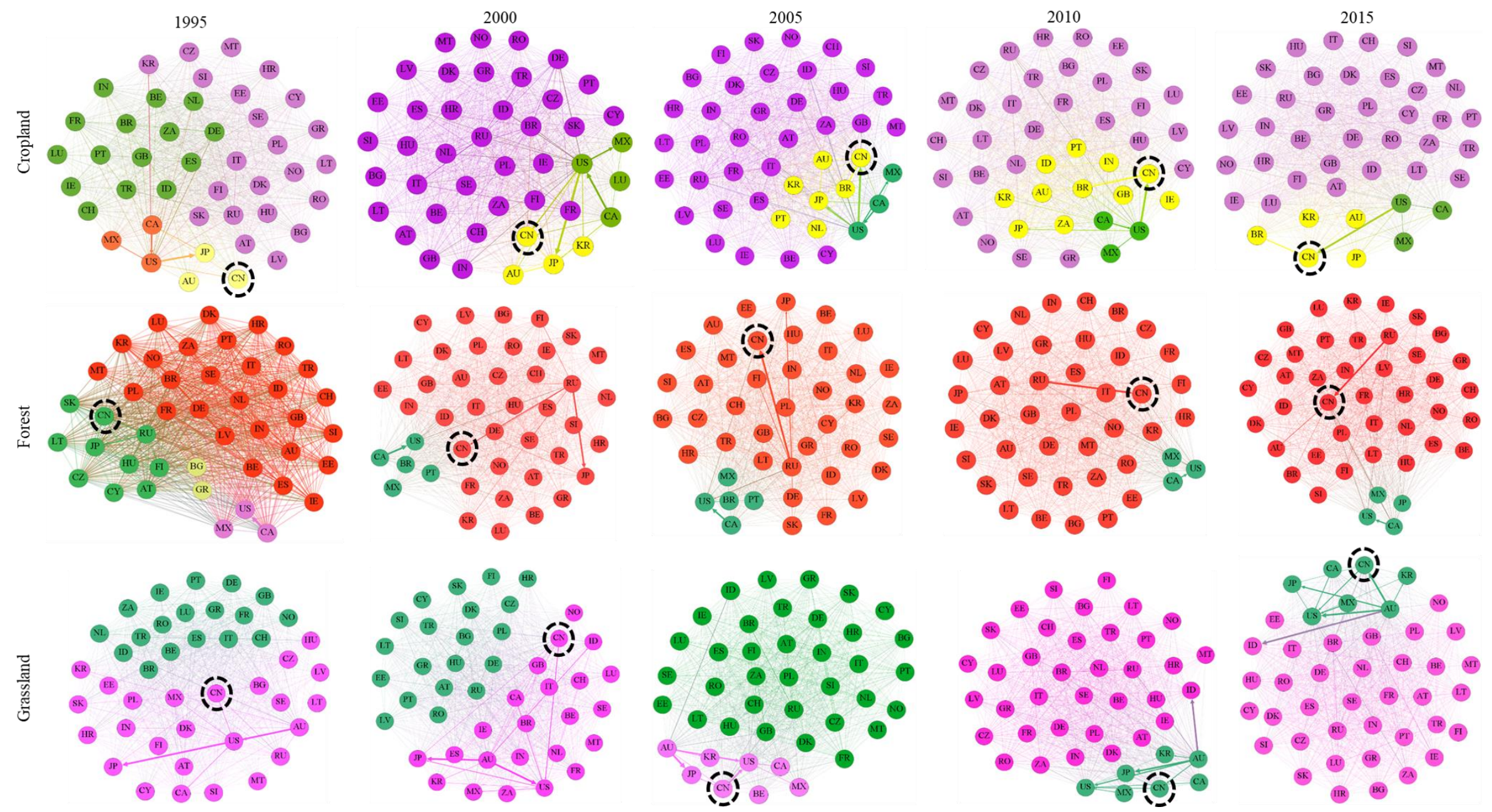

Figure 3 The patterns of China's virtual land (VL) network for cropland, forest and grassland. The colors represent clusters of countries with similar characteristics and close relations. 


\section{Reference}

Ali, T., Huang, J., Wang, J., Xie, W. (2016) Global footprints of water and land resources through China's food trade. Global Food Security 12, 139-145.

Ang, B., Xu, X. (2013) Tracking industrial energy efficiency trends using index decomposition analysis. Energy Economics 40, 1014-1021.

Ang, B.W. (2004) Decomposition analysis for policymaking in energy: which is the preferred method? Energy Policy 32, 1131-1139.

Ang, B.W., Zhang, F. (2000) A survey of index decomposition analysis in energy and environmental studies. Energy 25, 1149-1176.

Ang, B.W., Zhang, F., Choi, K.H. (1998) Factorizing changes in energy and environmental indicators through decomposition. Energy 23, 489-495.

Bai, X.M., Shi, P.J., Liu, Y.S. (2014) Realizing China's urban dream. Nature 509, 158-160.

Biggs, E.M., Bruce, E., Boruff, B., et al. (2015) Sustainable development and the water-energy-food nexus: A perspective on livelihoods. Environmental Science \& Policy 54, 389-397.

Blondel, V.D., Guillaume, J.L., Lambiotte, R., Lefebvre, E. (2008) Fast unfolding of communities in large networks. Journal of Statistical Mechanics Theory \& Experiment 2008, 155-168.

Bleischwitz, R., Spataru, C., VanDeveer, S. D., Obersteiner, M., van der Voet, E., Johnson, C., van Vuuren, D. P. (2018). Resource Nexus Perspectives towards the UN Sustainable Development Goals. Nature Sustainability 1, 737-743.

Bosire, C.K., Krol, M.S., Mekonnen, M.M., Ogutu, J.O., Leeuw, J.D., Lannerstad, M., Hoekstra, A.Y. (2016) Meat and milk production scenarios and the associated land footprint in Kenya. Agricultural Systems 145, 64-75.

Bosire, C.K., Ogutu, J.O., Said, M.Y., Krol, M.S., Leeuw, J.D., Hoekstra, A.Y. (2015) Trends and spatial variation in water and land footprints of meat and milk production systems in Kenya. Agriculture Ecosystems \& Environment 205, 36-47.

Bruckner, M., Fischer, G., Tramberend, S., Giljum, S. (2015) Measuring telecouplings in the global land system: A review and comparative evaluation of land footprint accounting methods. Ecological Economics 114, 11-21.

Bruckner, M., Giljum, S., Lutz, C., Wiebe, K.S. (2012) Materials embodied in international trade-Global material extraction and consumption between 1995 and 2005. Global Environmental Change 22, 568576 .

Chen, G.Q., Han, M.Y. (2015) Virtual land use change in China 2002-2010: Internal transition and trade imbalance. Land Use Policy 47, 55-65.

Cialani, C. (2007) Economic growth and environmental quality: an econometric and a decomposition analysis. Management of Environmental Quality: An International Journal 18, 568-577.

Cui, S., Shi, Y., Malik, A., Lenzen, M., Gao, B., Huang, W. (2016) A hybrid method for quantifying China's nitrogen footprint during urbanisation from 1990 to 2009. Environment International 97, $137-$ 145.

Dalin, C., Konar, M., Hanasaki, N., Rinaldo, A., Rodrigueziturbe, I. (2012) Evolution of the global virtual water trade network. Proceedings of the National Academy of Sciences of the United States of America 109, 5989-5994.

Evans, W.D., Chenery, H.B., Clark, P.G., Cao-Pinna, V. (1955) The Structure and Growth of the Italian Economy. Econometrica 23, 110-111.

Fischer-Kowalski, M., Dittrich, M., Eisenmenger, N., Ekins, P., Fulton, J., Kastner, T., Schandl, H., West, 
J., Wiedman, T. (2015) International Trade in Resources: A Biophysical Assessment. Report of the International Resource Panel. United Nations Environment Programme Paris.

Gao, C., Sun, M., Shen, B. (2015) Features and evolution of international fossil energy trade relationships: A weighted multilayer network analysis. Applied Energy 156, 542-554.

Gao, J.L., Chen, W., Yuan, F. (2017) Spatial restructuring and the logic of industrial land redevelopment in urban China: I. Theoretical considerations. Land Use Policy 68, 604-613.

Geng, Y., Sarkis, J., Ultiati, S., Zhang, P. (2013) Measuring China's circular economy. Science. 339: 1526-1527.

Geng, Y., Sarkis, J., Bleischwitz, R. (2019). How to globalize the circular economy. Nature 565, 153155 .

Giljum, S., Hinterberger, F., Lutz, C., Meyer, B. (2009) Accounting and Modelling Global Resource Use. Springer Netherlands.

Giljum, S., Wieland, H., Lutter, S. (2016) Identifying priority areas for European resource policies: a MRIO-based material footprint assessment. Journal of Economic Structures 5, 1-24.

Han, M., Chen, G. (2018) Global arable land transfers embodied in Mainland China's foreign trade. Land Use Policy 70, 521-534.

Hertwich, E.G., Peters, G.P. (2009) Carbon footprint of nations: a global, trade-linked analysis. Environmental Science \& Technology 43, 6414-6420.

Hoekstra, A.Y., Mekonnen, M.M. (2012) The water footprint of humanity. Proceedings of the National Academy of Sciences of the United States of America 109, 3232-3237.

Hoekstra, A.Y., Wiedmann, T.O. (2014) Humanity's unsustainable environmental footprint. Science 344, 1114-1117.

Hoffren, J., Luukkanen, J., Kaivo-Oja, J. (2000) Statistical decomposition modelling on the basis of material flow accounting. Journal of Industrial Ecology 4, 515-523.

Ivanova, D., Stadler, K., Steen-Olsen, K., Wood, R., Vita, G., Tukker, A., Hertwich, E.G. (2016) Environmental Impact Assessment of Household Consumption. Journal of Industrial Ecology 20, 526536.

Jungnitz, A. (2008) Decomposition analysis of greenhouse gas emissions and energy and material inputs in Germany. Resource Productivity, Environmental Tax Reform and Sustainable Growth in Europe.

Khoo, H.H. (2015) Review of bio-conversion pathways of lignocellulose-to-ethanol: Sustainability assessment based on land footprint projections. Renewable \& Sustainable Energy Reviews 46, 100-119. Lee, Y.J. (2015) Land, carbon and water footprints in Taiwan. Environmental Impact Assessment Review $54,1-8$.

Lenzen, M., Moran, D., Kanemoto, K., Foran, B., Lobefaro, L., Geschke, A. (2012) International trade drives biodiversity threats in developing nations. Nature 486, 109-112.

Leontief, W.W. (1936) Quantitative Input-Output Relations in the Economic System of the United States. Review of Economics \& Statistics 18, 105-125.

Li, Y.H., Wu, W.H., Liu, Y.S. (2018) Land consolidation for rural sustainability in China: Practical reflections and policy implications. Land Use Policy 74, 137-141.

Liu, Y.S. (2018) Introduction to land use and rural sustainability in China. Land Use Policy 74, 1-4.

Liu, Y.S., Fang, F., Li, Y.H. (2014) Key issues of land use in China and implications for policy making. Land Use Policy 40, 6-12.

Liu, Y.S., Li, Y.H. (2017). Revitalize the world's countryside. Nature 548 (7667), 275-277.

Liu, Y.S., Li, J.T., Yang, Y.Y. (2018) Strategic adjustment of land use policy under the economic 
transformation. Land Use Policy 74, 5-14.

Matthews, A., Salvatici, L., Scoppola, M. (2017) Trade impacts of agricultural support in the EU. International Agricultural Trade Research Consortium. Commissioned Paper.

Miller, R.E., Blair, P.D. (2009) Input-output analysis: foundations and extensions. Cambridge University Press.

Ministry of Land Resources (2005-2010). Land and Resources of China Statistical Yearbook. Geological Publishing House, Beijing.

Mont, O., Bleischwitz, R. (2007) Sustainable Consumption and Resource Management in the Light of Life Cycle Thinking. European Environment 17, 59-76.

Nkonya, E., Anderson, W., Kato, E., Koo, J., Mirzabaev, A., Braun, J.V., Meyer, S. (2016) Global Cost of Land Degradation. Springer International Publishing.

Nordborg, M., Arvidsson, R., Finnveden, G., Cederberg, C., Sörme, L., Palm, V., Stamyr, K., Molander, S. (2017) Updated indicators of Swedish national human toxicity and ecotoxicity footprints using USEtox 2.01. Environmental Impact Assessment Review 62, 110-114.

O’Brien, M., Schütz, H., Bringezu, S. (2015) The land footprint of the EU bioeconomy: Monitoring tools, gaps and needs. Land Use Policy 47, 235-246.

Peng, X. (2011) China's demographic history and future challenges. Science 333, 581-587.

Peters, G.P., Minx, J.C., Weber, C.L., Edenhofer, O. (2011) Growth in emission transfers via international trade from 1990 to 2008. Proceedings of the National Academy of Sciences of the United States of America 108, 8903-8908.

Qian, Y., Dong, H., Geng, Y., Zhong, S., Tian, X., Yu, Y., Chen, Y., Moss, D. (2018) Water footprint characteristic of less developed water-rich regions: case of Yunnan, China. Water Research. 141: 208216.

Qiang, W., Liu, A., Cheng, S., Kastner, T., Xie, G. (2013) Agricultural trade and virtual land use: The case of China's crop trade. Land Use Policy 33, 141-150.

Rees, W.E., Wackernagel, M. (1992) Ecological Footprints and Appropriated Carrying Capacity: Measuring the Natural Capital Requirements of the Human Economy. Focus 6, 121-130.

Ridoutt, B.G., Page, G., Opie, K., Huang, J., Bellotti, W. (2014) Carbon, water and land use footprints of beef cattle production systems in southern Australia. Journal of Cleaner Production 73, 24-30.

Ruiter, H.D., Macdiarmid, J.I., Matthews, R.B., Kastner, T., Lynd, L.R., Smith, P. (2017) Total global agricultural land footprint associated with UK food supply 1986-2011. Global Environmental Change $43,72-81$.

Salvo, G., Simas, M.S., Pacca, S.A., Guilhoto, J.J.M., Tomas, A.R.G., Abramovay, R. (2015) Estimating the human appropriation of land in Brazil by means of an Input-Output Economic Model and Ecological Footprint analysis. Ecological Indicators 53, 78-94.

Stadler, K., Wood, R., Bulavskaya, T., Södersten, C.J., Simas, M., Schmidt, S., Usubiaga, A., AcostaFernández, J., Kuenen, J., Bruckner, M. (2018) EXIOBASE 3: Developing a time series of detailed environmentally extended multi-regional input-output tables. Journal of Industrial Ecology 22, 502-515. Steenolsen, K., Weinzettel, J., Cranston, G., Ercin, A.E., Hertwich, E.G. (2012) Carbon, Land, and Water Footprint Accounts for the European Union: Consumption, Production, and Displacements through International Trade. Environmental Science \& Technology 46 (20), 10883-10891.

Tian, X., Geng, Y., Dong, H., Dong, L., Fujita, T., Wang, Y., Zhao, H., Wu, R., Liu, Z., Sun, L. (2015) Regional household carbon footprint in China: a case of Liaoning province. Journal of Cleaner Production 114, 401-411. 
Tian, X., Geng, Y., Sarkis, J., Zhong, S. (2018a) Trends and features of embodied flows associated with international trade based on bibliometric analysis. Resources Conservation \& Recycling 131, 148-157. Tian, X., Geng, Y., Ulgiati, S. (2016) An emergy and decomposition assessment of China-Japan trade: Driving forces and environmental imbalance. Journal of Cleaner Production 141, 359-369.

Tian, X., Sarkis, J., Geng, Y., Qian, Y.Y., Gao, C.X., Bleischwitze, R., Xu, Y. (2018b) Evolution of China's water footprint and virtual water trade: A global trade assessment. Environment international 121, 178 188 .

Tomei, J., Ravindranath, D. (2017) Governing land in the global south. Routledge Handbook of the Resource Nexus. Routledge 332-343.

Tukker, A., Bulavskaya, T., Giljum, S., Koning, A.D., Lutter, S., Simas, M., Stadler, K., Wood, R. (2016) Environmental and resource footprints in a global context: Europe's structural deficit in resource endowments. Global Environmental Change 40, 171-181.

Tukker, A., Dietzenbacher, E. (2013) Global multiregional Input-Output frameworks: An introduction and outlook. Economic Systems Research 25, 1-19.

Turner, B.L., Lambin, E.F., Reenberg, A. (2007) The emergence of land change science for global environmental change and sustainability. Proceedings of the National Academy of Sciences of the United States of America 104 (52), 20666-20671.

Vivanco, D.F., Sprecher, B., Hertwich, E. (2017) Scarcity-weighted global land and metal footprints. Ecological Indicators 83, 323-327.

Weinzettel, J., Hertwich, E.G., Peters, G.P., Steen-Olsen, K., Galli, A. (2013) Affluence drives the global displacement of land use. Global Environmental Change 23, 433-438.

Weinzettel, J., Kovanda, J. (2011) Structural decomposition analysis of raw material consumption. Journal of Industrial Ecology 15, 893-907.

Wiedmann, T. (2009) A first empirical comparison of energy Footprints embodied in trade-MRIO versus PLUM. Ecological Economics 68, 1975-1990.

Wu, R., Geng, Y., Dong, H., Fujita, T., Tian, X. (2016) Changes of $\mathrm{CO}_{2}$ emissions embodied in ChinaJapan trade: drivers and implications. Journal of Cleaner Production 112, 4151-4158.

Yang, S., Chen, B., Wakeel, M., Hayat, T., Alsaedi, A., Ahmad, B. (2017) PM 2.5 footprint of household energy consumption. Applied Energy 227, 375-383.

Yang, Y.Y., Liu, Y.S., Li, Y.R., Li, J.T. (2018) Measure of urban-rural transformation in Beijing-TianjinHebei region in the new millennium: Population-land-industry perspective. Land Use Policy 79, 595 608 .

Zhang, K., Song, C., Zhang, Y., Zhang, Q. (2017) Natural disasters and economic development drive forest dynamics and transition in China. Forest Policy \& Economics 76, 56-64.

Zhou, Y., Guo, L.Y., Liu, Y.S. (2019). Land consolidation boosting poverty alleviation in China: Theory and practice. Land Use Policy 82, 339-348.

Zhu, Q.H., Li, Y., Geng, Y., Qi, Y. (2013). Green food consumption intention, behaviors and influencing factors among Chinese consumers. Food Quality and Preference 28, 279-286. 